\title{
KEEFEKTIFAN URUTAN PEMBELAJARAN KETERAMPILAN GERAK RENANG
}

\author{
F.X. Sugiyanto \\ FIK Yogyakarta State University (E-mail: fxsugianto@ymail.com; \\ HP: 081328783733)
}

\begin{abstract}
The Effectiveness of Learning Sequences in Swimming Skills. This study aims to investigate the appropriateness and effectiveness of learning sequences in swimming skills after the students mastered the crawl stroke. The sequences were that from the crawl stroke to the breast stroke and that from the crawl stroke to the back stroke. This study was a quasi-experimental study using the pretest-posttest group design. The population comprised students of the Faculty of Sports Sciences, Yogyakarta State University. The sample was selected using the purposive sampling technique. The results showed that the sequence from the crawl stroke to the back stroke was more efficient than that from the crawl stroke to the breast stroke in terms of the mastery of swimming skills.
\end{abstract}

Keywords: learning sequences, crawl stroke, back stroke, breast stroke

\section{PENDAHULUAN}

Dalam Kurikulum Program Studi (Prodi) Pendidikan Kepelatihan Olahraga $(\mathrm{PKO})$ Jurusan Pendidikan Kepelatihan (PKL) Fakultas Ilmu Keolahragaan (FIK) Universitas Negeri Yogyakarta (UNY), salah satu di antaranya terdapat mata kuliah wajib, yaitu keterampilan gerak renang. Namun, dalam beberapa angkatan banyak mahasiswa yang tidak lulus mata kuliah keterampilan gerak renang tersebut. Rata-rata mahasiswa hanya memperoleh nilai $\mathrm{K}$ dan beberapa di antaranya mendapat nilai D. Data nilai keterampilan gerak renang mahasiswa angkatan tahun 2004-2006 yang memperoleh nilai D sejumlah 21 mahasiswa, sedang yang mendapat K 38 mahasiswa.

Banyak faktor yang ikut mempengaruhi keberhasilan mahasiswa dalam menguasai keterampilan gerak renang. Namun, berdasarkan hasil pengamatan dan wawancara pengajar renang dengan mahasiswa, ternyata beberapa hal yang menyebabkan mahasiswa gagal menguasai keterampilan gerak renang antara lain (1) perasaan trauma mahasiswa terhadap air karena pengalaman sebelumnya yang kurang menyenangkan; (2) Mahasiswa sama sekali belum pernah mengenal olahraga renang sehingga waktu yang dimiliki untuk menguasai keterampilan gerak renang kurang memadai; (3) banyak keterampilan gerak renang yang harus dikuasai dalam satu semester, yaitu: renang gaya bebas (crawl) 100 meter, gaya dada 50 meter, menyelam sejauh 25 meter, menyelam di kedalaman 6-7 meter, renang menolong 25 meter, mengapung selama 30 menit; dan (4) kurikulum yang su- 
dah tidak memadai sehingga perlu ditinjau ulang untuk direvisi. Seperti yang diyatakan oleh Nasution (1982:210) bahwa pembaruan kurikulum merupakan hal biasa sebab mempertahankan kurikulum yang ada akan merugikan anakanak dan fungsi kurikulum itu sendiri.

Untuk itu, diperlukan pembaruan dalam pendidikan, khususnya pembelajaran keterampilan gerak renang guna mengubah kebiasaan lama dan model urutan (sequence) penyajian materi. Dari beberapa masalah seperti tersebut di atas, perubahan kurikulum merupakan masalah yang sangat mendesak untuk diadakan pembaharuan. Pembaharuan yang dimaksud adalah model urutan penyajian pada mata kuliah keterampilan gerak renang. Selama ini, dari gaya crawl ke gaya dada perlu ditinjau ulang, dan dicarikan alternatif lain dengan model urutan dari gaya crawl ke gaya punggung.

Keterampilan gerak renang yang harus dikuasai oleh mahasiswa dalam satu semester materi meliputi: renang gaya bebas (crawl) sejauh 100 meter, renang gaya dada 50 meter, menyelam memanjang sejauh 25 meter, menyelam di kedalaman 6-7 meter, renang menolong 25 meter, dan keterampilan mengapung selama 30 menit. Artinya, dalam satu semester mahasiswa dinyatakan lulus jika semua materi sajian tersebut memenuhi standar nilai yang telah ditetapkan. Dalam menetapkan kelulusan mahasiswa, mengegunakan indikator ketepatan teknik berenang dan catatan waktu yang dicapai saat ujian praktik dari semua materi sajian tersebut di atas. Nampaknya, materi yang cukup banyak yang harus dikuasai oleh maha- siswa tersebut menghambat kelulusan pada mata kuliah keterampilan gerak renang. Selain itu, kemungkinan model urutan sajian materi renang perlu dicoba diubah disesuaikan dengan teori pembelajaran renang.

Fakta menunjukkan bahwa mahasiswa banyak yang tidak lulus mata kuliah keterampilan gerak renang tersebut menimbulkan keprihatinan bagi pengajar sehingga peneliti yang sekaligus pengajar keterampilan gerak renang berkeinginan dan terdorong untuk mencoba menerapkan model pembelajaran renang yang efektif dan efisien. Model pembelajaran yang diterapkan adalah mengubah urutan penyajian, setelah mahasiswa memiliki keterampilan renang gaya crawl, urutan penyajian berikutnya yang lebih cepat dikuasai oleh mahasiswa apakah diberikan renang gaya punggung atau renang gaya dada?

Selama ini, urutan penyajian setelah renang gaya crawl adalah renang gaya dada dan dilajutkan renang gaya punggung (crawl-dada-punggung). Namun, kenyataannya urutan materi tersebut mengakibatkanbanyak mahasiswa yang tidak lulus sehingga perlu membandingkan model urutan dari renang gaya crawl ke renang gaya punggung (crawlpunggung) dan dari renang gaya crawl ke renang gaya dada (crawl-dada). Untuk itu, konsep model yang dicobakan kepada mahasiswa adalah dengan prasyarat bahwa urutan dalam pembelajaran keterampilan gerak renang dimulai dari renang gaya crawl terlebih dahulu. Setelah mahasiswa memiliki keterampilan renang gaya crawl, renang gaya punggung atau renang gaya dada yang lebih cepat dikuasai oleh mahasiswa. 
Berdasarkan uraian di atas, maka rumusan masalahnya adalah: manakah model urutan sajian yang lebih efektif (cepat) dikuasai oleh mahasiswa pada mata kuliah keterampilan gerak renang dari gaya crawl ke gaya dada atau dari gaya crawl ke gaya punggung?

Diharapkan melalui penelitian ini dapat diketahui model urutan yang tepat bagi mahasiswa dalam menguasai mata kuliah keterampilan gerak renang. Setelah mahasiswa menguasai renang gaya crawl dalam waktu separuh tatap muka yang tersedia untuk materi keterampilan gerak renang, maka yang efektif diberikan terlebih dahulu model crawldada atau crawl-punggung. Dengan mengetahui model urutan penyajian yang tepat dan efektif dapat dimanfaatkan sebagai upaya dalam pengembangan kurikulum, khususnya untuk mata kuliah keterampilan gerak renang. Model urutan penyajian yang dipilih ikut menentukan keberhasilan mahasiswa dalam menguasai keterampilan gerak renang. Selain itu, mahasiswa diuntungkan untuk menguasai keterampilan gerak renang dalam waktu yang relatif lebih singkat. Dengan kata lain, tingkat kelulusan mahasiswa pada mata kuliah keterampilan gerak renang menjadi lebih baik dan lebih banyak.

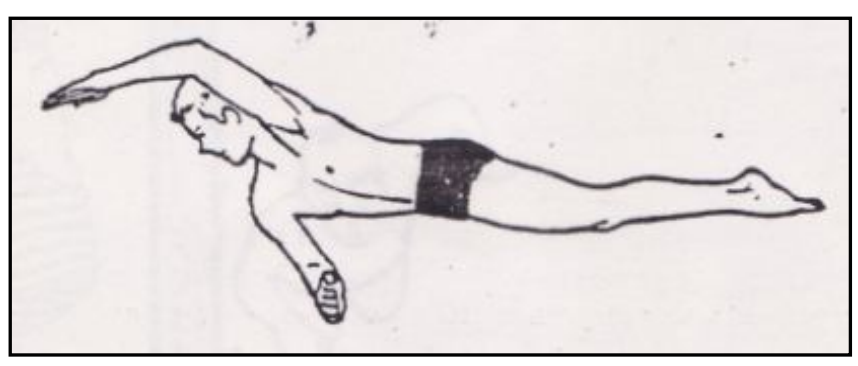

Gambar 1. Renang Gaya Crawl
Pengertian renang gaya crawl atau gaya rimau (the front crawl stroke) menurut Abdoellah dkk. (1981:278) adalah berenang dengan posisi badan menelungkup, lengan kanan dan kiri digerakkan bergantian untuk mendayung dari depan ke belakang. Tungkai digerakkan naik turun secara bergantian untuk mencambuk air agar menghasilkan daya dorong ke arah depan. Artinya, gerakan tungkai tersebut yang akan mengakibatkan laju badan perenang meluncur ke depan. Untuk lebih jelas, renang gaya crawl dapat dilihat pada Gambar 1.

Pengertian renang gaya punggung (the back crawl stroke) adalah berenang dengan posisi badan terlentang, lengan kanan dan kiri digerakkan secara bergantian untuk mendayung. Tungkai digerakkan naik turun secara bergantian untuk mencambuk air agar mendapatkan daya dorong ke depan sehingga tubuh perenang dapat meluncur ke depan. Gerakan renang gaya punggung dapat dilihat pada Gambar 2.

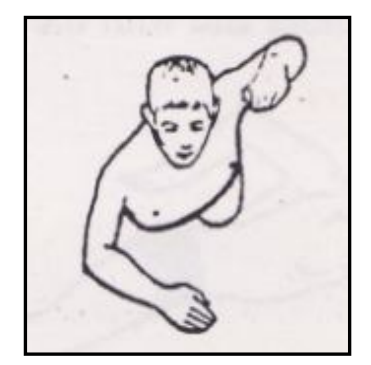



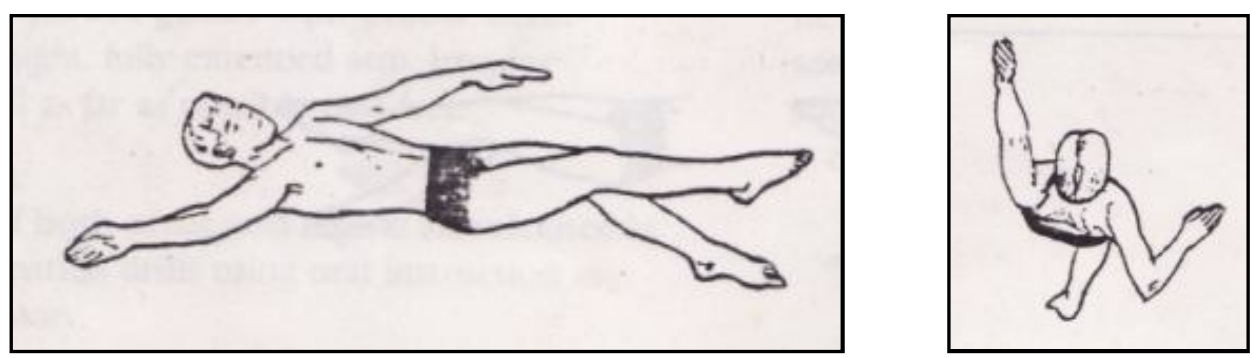

Gambar 2. Renang Gaya Punggung

Renang gaya dada (the breast stroke) sering juga disebut renang gaya katak, karena renang gaya dada mirip sekali dengan gerakan katak waktu berenang. Renang gaya dada adalah berenang dengan kedua tangan harus didorongkan ke muka secara bersama-sama dari arah dada pada saat atau di bawah permukaan air, lalu dikembangkan ke samping dan dibawa ke belakang kembali dengan serempak dan simetris. Posisi badan telungkup dan kedua bahu sejajar

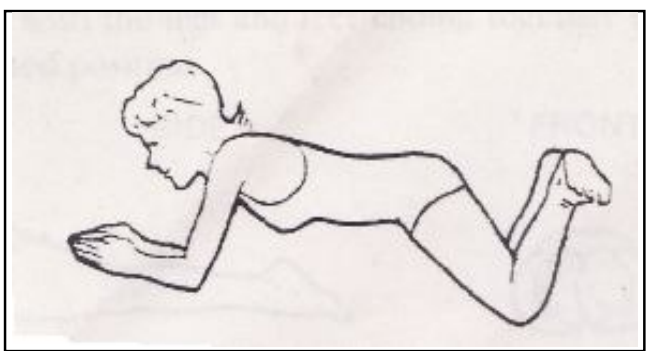

\section{Gambar 3. Renang Gaya Dada}

Setelah mencermati gambar 1 dan 2 nampak sekali bahwa ada kesamaan gerak, hanya saja yang berbeda pada posisinya yaitu telungkup untuk gaya crawl dan telentang untuk gaya punggung. Untuk gerakan tungkai dan lengan memiliki kesamaan guna mendorong badan agar dapat melaju ke de-

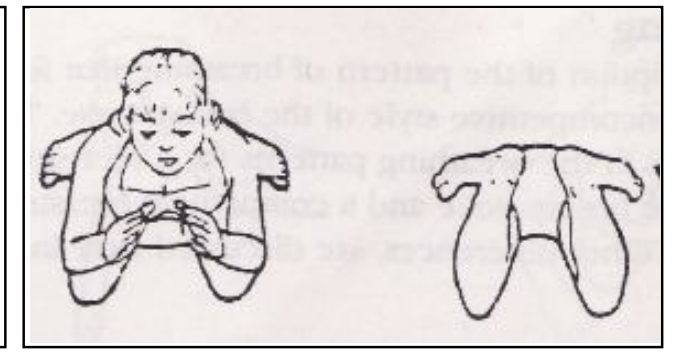

dengan permukaan air. Selanjutnya, kedua kaki ditarik bersama-sama ke arah badan, lutut ditekuk dan terbuka agar siap menendang air ke belakang untuk mendapatkan daya dorong ke depan. Sesudah itu, dilanjutkan dengan kedua kaki digerakkan melingkar ke luar dan dirapatkan kembali. Semua gerak kaki harus dilakukan secara serempak, simetris dan dalam bidang yang sama datar, seperti terlihat pada Gambar 3 berikut.

pan dengan cepat. Dengan demikian, diduga model urutan dari gaya crawl ke gaya punggung mahasiswa lebih cepat menguasainya karena ada transfer keterampilan pada gerakan lengan dan tungkai.

Selanjutnya, jika dibandingkan antara Gambar 1 (crawl) dan Gambar 2 
(punggung) dengan Gambar 3 (dada), nampak sekali perbedaan gerakan pada lengan dan tungkai. Untuk Gambar 3 (dada), memerlukan koordinasi gerak lengan dan tungkai yang lebih kompleks daripada renang gaya crawl dan punggung. Selain itu, perubahan dari gaya crawl ke gaya dada tidak terjadi transfer keterampilan gerak pada gerakan lengan dan tungkai. Dengan demikian, diduga model urutan dari gaya crawl ke gaya dada lebih lambat (lama) dikuasai oleh mahasiswa dikarenakan tidak terjadi transfer keterampilan pada gerakan lengan dan tungkai.

Fenomena yang berkembang di masyarakat bahwa belajar berenang akan lebih mudah dengan mengajarkan renang gaya dada (gaya katak) terlebih dahulu sebelum gaya crawl atau sebaliknya, darigaya crawl terlebih dahulu baru gaya dada. Hal itu terbukti bahwa para pelatih (guru) renang di beberapa les privat di kolam renang umumnya menerapkan model dari gaya crawl ke gaya dada. Bahkan, beberapa pengajar keterampilan gerak renang dari FIK UNY pun masih ada yang berpendapat seperti itu. Para pengajar keterampilan gerak renang FIKUNY menerapkan model tersebut bukan tanpa dasar, sebab dalam Kurikulum 2002 FIK UNY, mata kuliah keterampilan gerak renang dengan kode IKF230 silabusnya menerapkan model urutan penyajian dari gaya dada ke gaya crawl atau dari gaya crawl ke gaya dada (Kurikulum 2002 FIK UNY, 2006:35). Pada dasarnya, kedua model sajian tersebut tidak seluruhnya salah karena pada awal abad ke-19 yang diajarkan di sekolah-sekolah umum dan yang dipakai dalam perlombaan adalah renang gaya katak saja. Oleh karena yang diajarkan di sekolah-sekolah hanya renang gaya katak saja, maka renang gaya ini dinamakan juga dengan renang gaya sekolah (schoolslag) (Tjiang dan Tarigan, 1962:55).

Teori yang baru menyatakan bahwa urutan dalam belajar berenang sudah tidak lagi mengikuti urutan dari gaya dada ke gaya crawl atau sebaliknya seperti tersebut di atas. Counsilman (1977: 144) menyatakan bahwa renang gaya rimau (gaya crawl) merupakan persyaratan untuk memahami atau mempelajari ke tiga gaya renang berikutnya, yaitu: renang gaya punggung, gaya kupukupu (gaya dolphin), dan renang gaya dada. Hal senada juga dinyatakan oleh The Canadian Redcroos Society (1974: 48-64) bahwa model urutan sajiannya, yaitu: renang gaya rimau, gaya punggung, dan renang gaya dada. Colwin (1977: 45-69) berpendapat bahwa dalam mempelajari keterampilan gerak renang dimulai dari gaya rimau, gaya kupukupu, gaya punggung, dan gaya dada. Dari ke tiga pendapat tersebut, diketahui bahwa gaya rimau merupakan gaya yang harus dipelajari terlebih dahulu sebelum mempelajari ketiga gaya renang yang lain. Selanjutnya, renang gaya dada merupakan gaya yang terakhir untuk dipelajari oleh para perenang pemula.

Pada dasarnya, renang gaya dada ada dua macam, yaitu (1) gaya tradisional (the traditional style); dan (2) renang gaya dada yang seperti gaya dolphin (the dolphin style breast stroke) (Maglischo, 1982:129). Renang gaya tradisional banyak digunakan oleh perenang-perenang Amerika. Ciri-ciri re- 
nang gaya dada yang tradisional adalah posisi badan rata-rata air dengan pinggul tetap pada atau dekat permukaan air dan bahu seluruhnya terletak dalam air. Pernapasan dilakukan dengan cara mengangkat dan menurunkan kepala sehingga posisi rata-rata air dari badan dan kaki tidak terganggu.

Renang gaya dada yang seperti gaya dolphin (the dolphin style breast stroke) di mana posisi pinggul lebih rendah, dan bahu di bawa ke luar permukaan air ketika mengambil napas. Gaya ini banyak digunakan oleh perenang Eropa Timur. Howard Firby menyebut renang gaya ini dengan istilah renang gaya dada alamiah (the natural style breast stroke). Gaya dada yang akan dipelajari adalah gaya dada yang menyerupai gaya dolphin. Oleh karena itu, apabila seseorang telah menguasai gaya dolphin, orang tersebut tidak akan mengalami kesulitan dalam mempelajari renang gaya dada.

Berdasarkan kajian teori tersebut, maka yang dapat dianggap sebagai renang dasar adalah gaya crawl (rimau) dan gaya punggung. Selanjutnya, apabila renang gaya crawl dan gaya punggung diajarkan berurutan akan banyak memperoleh keuntungan karena adanya kemiripan pada gerakan lengan dan tungki dari kedua gaya tersebut. Maglischo (1982:169) menyatakan bahwa sudah sejak awal dari perlombaanperlombaan renang, renang gaya punggung merupakan kebalikan dari versi gaya crawl (gaya rimau). Keyakinan bahwa gaya punggung benar-benar merupakan kebalikan dari gaya crawl diperkuat oleh teori daya angkat (lift theory) yang diterapkan pada mekanika dari kedua gaya tersebut, di mana kesamaan di antara kedua gaya itu sama persis. The Canadian Red Cross Society (1974:56) beranggapan bahwa gaya punggung adalah salah satu gaya yang mudah dipelajari dan diajarkan. Di samping itu, pada renang gaya punggung tidak ada masalah dalam pernapasan karena dapat dilakukan secara alamiah. Gerakan lengan dari kedua gaya tersebut memiliki kesamaan, yaitu menggerakkan lengan kanan dan kiri secara bergantian saat mendayung air. Gerakan tungkai pada gaya crawl dapat menggunakan pukulan flutter kick, demikian juga pada gaya punggung, hanya pada gaya punggung agak lebih dalam.

Dilihat dari gerak tungkai kedua gaya renang (crawl dan punggung) tersebut sudah sangat menguntungkan. Jika seorang perenang belajar pukulan tungkai gaya crawl, otomatis orang tersebut juga sudah belajar gerak tungkai untuk gaya punggung. Kondisi seperti itu yang menyebabkan para perenang lebih efisien dalam belajar berenang dilihat dari segi waktu belajar. Namun demikian, ada satu kesulitan dalam belajar gaya punggung, yaitu timbulnya perasaan takut perenang pada waktu meletakkan kepala ke belakang karena perenang tidak dapat melihat ke depan secara langsung. Faktanya, kesulitan ini tidak besar pengaruhnya bila dibandingkan dengan keuntungan-keuntungan yang diperoleh dalam menguasai keterampilan gerak renang gaya punggung. Beberapa keuntungan tersebut tidak akan didapat apabila model urutan penyajian keterampilan gerak renang dari gaya crawl ke gaya dada.

Berdasarkan kajian teoretik di atas, model urutan penyajian keterampilan 
renang setelah gaya crawl akan lebih efektif bila dilanjutkan dengan gaya punggung daripada setelah gaya crawl dilanjutkan dengan gaya dada. Hal ini dikarenakan pukulan tungkai pada gaya crawl mirip dengan pukulan tungkai pada gaya punggung, yang berbeda hanya posisi badannya telungkup untuk gaya crawl dan telentang untuk gaya punggung. Oleh karena itu, seorang yang menguasai pukulan tungkai gaya crawl otomatis ada transfer keterampilan yang lebih tinggi dalam mempelajari pukulan tungkai gaya punggung. Dengan demikian, model gaya crawl ke gaya punggung akan mempersingkat waktu seseorang dalam mempelajari keterampilan berenang gaya punggung. Dengan jumlah tatap muka yang terbatas dan keterampilan yang dipelajari

$\begin{array}{lc}\text { KELOMPOK } & \text { PRE-TEST } \\ \text { Kontrol } & O \\ \text { Eksperimen } & O\end{array}$

Sebelum diberiperlakuan, kedua kelompok tersebut terlebih dahulu dites awal (pretest) dengan berenang gaya crawl sejauh 25 meter untuk menentukan tingkat keterampilan berenang setiap sampel. Selama diberiperlakuan, kedua kelompokselalu dipantau oleh judges atau sebagaibentukdari tes akhir (posttest) untuk mengetahui tingkat kecepatan sampel dalam menguasai keterampilan renang dari gaya crawl ke gaya dada atau dari gaya crawl ke gaya punggung. Bentuk tesnya adalah berenang dengan gaya dada untuk kelompok kontrol dan gaya punggung untuk kelompok eksperimen, keduanya menempuh jarak sejauh 25 meter. cukup banyak (enam macam keterampilan), maka model urutan penyajian dari gaya crawl ke gaya punggung lebih menguntungkan bagi mahasiswa dalam menguasai keterampilan gerak renang.

\section{METODE}

Metode penelitian yang digunakan adalah eksperimen semu (quasi-experimental) dengan pretest-posttest group design. Penelitian kuasi eksperimen ini menggunakan dua kelompok, yaitu kelompok kontrol dan kelompok eksperimen. Kelompok kontrol adalah urutan pembelajaran renang gaya crawl-dada, sedangkan kelompok eksperimen adalah urutan pembelajaran renang gaya crawl-punggung. Selanjutnya, desain penelitiannya digambarkan sebagai berikut.

$\begin{array}{cc}\text { PERLAKUAN } & \text { POST-TEST } \\ \text { crawl-dada }\left(X_{1}\right) & O \\ \text { crawl-punggung }\left(X_{2}\right) & O\end{array}$

Populasi penelitian adalah mahasiswa FIK UNY. Teknik pengambilan sampel secara purposive sampling. Artinya, sampel bertujuan karena penentuan sampel didasarkan atas adanya tujuan tertentu atau dengan pertimbangan tertentu (Arikunto, 1996:127; Sugiyono, 2007:112-113 dan 124). Pertimbangan yang dipakai dalam menentukan sampel adalah (1) mahasiswa Prodi PKO kelas A dan B yang mengambil mata kuliah keterampilan gerak renang pada semester genap (Februari-Juni 2007); (2) mahasiswa belum pernah mengambil mata kuliah keterampilan gerak renang sebelumnya (bukan mahasiswa yang mengulang); dan (3) mahasiswa meme- 
nuhi syarat dan dikelompokkan berdasarkan hasil tes renang gaya crawl.

Terdapat 74 mahasiswa yang mengikuti mata kuliah keterampilan gerak renang. Dengan dibantu 3 orang judges, mahasiswa tersebut dites keterampilan renang gaya crawl sejauh 25 meter. Tujuan tes untuk mengelompokkan tingkat keterampilan mahasiswa dalam berenang, hasilnya terdapat 3 tingkat keterampilan yaitu: kelompok baik, sedang, dan kelompok kurang terampil. Dari 74 mahasiswa tersebut yang memenuhi syarat menguasai renang gaya crawl sejumlah 65 mahasiswa, sedang 9 mahasiswa dinyatakan belum dapat berenang gaya crawl. Jumlah sampel kelompok keterampilan baik 26 mahasiswa, kelompok sedang 23 mahasiswa, dan kelompok yang berketerampilan kurang 16 mahasiswa.

Alat yang digunakan untuk mengumpulkan data antara lain blanko daftar hadir mahasiswa, alat tulis, dan dosen ahli (3 orang pengajar renang) sebagai judges. Definisi operasional keterampilan gerak renang adalah kemampuan mahasiswa untuk mengkoordinasikan gerak tungkai, lengan, dan pernafasan saat berenang pada gaya renang yang diujikan (dada atau punggung) dalam menempuh jarak 25 meter. Selanjutnya, setiap kali pertemuan, setiap kelompok selalu diamati oleh judges untuk mengetahui tingkat kecepatan penguasaan mahasiswa terhadap keterampilan renang gaya dada dan keterampilan renang gaya punggung. Dari hasil pengamatan (pantauan) tersebut akan dapat diketahui setelah berapa kali pertemuan mahasiswa dapat me- nguasai setiap gaya (dada atau punggung) tersebut pada jarak 25 meter.

\section{HASIL DAN PEMBAHASAN}

Jalannya penelitian, pada pertemuan pertama menentukan kriteria sampel. Dengan dibantu oleh tiga orang judges, 74 mahasiswa dites keterampilan berenang gaya crawl sejauh 25 meter. Hasilnya 65 mahasiswa memenuhi syarat sebagai sampel penelitian, sedang 9 mahasiswa dinyatakan belum dapat berenang gaya crawl. Berdasarkan hasil tes ada tiga kelompok klasifikasi keterampilan berenang, yaitu: kelompok baik 26 mahasiswa, kelompok sedang 23 mahasiswa, dan kelompok kurang 16 mahasiswa. Dari setiap kelompok baik, sedang, dan kurang tersebut masing-masing dijadikan 2 kelompok dengan cara belah dua (split-half), yaitu genap-ganjil. Selanjutnya, dengan cara random satu kelompok diberi pelajaran renang gaya crawl-dada, dan satu kelompok lagi diberi pelajaran renang gaya crawl-punggung.

Pada pertemuan kedua dan seterusnya, setiap kelompok diajar oleh seorang dosen dengan materi sajian keterampilan renang gaya punggung, dan satu kelompok lagi diajar oleh dosen yang berbeda dengan materi sajian keterampilan renang gaya dada. Setiap kelompok diberika alokasi waktu untuk setiap tatap muka selama 100 menit. Maksimal tatap muka dilakukan sebanyak 12 kali pertemuan.

Materi yang disajikan untuk renang gaya punggung adalah: (1) meluncur; (2) pukulan tungkai gaya punggung; (3) pukulan (kayuhan) lengan gaya punggung; (4) latihan pernapasan; dan (5) la- 
tihan kombinasi renang gaya punggung. Selanjutnya, materi yang disajikan untuk renang gaya dada adalah: (1) meluncur; (2) gerak pukulan tungkai gaya dada; (3) pukulan (gerakan) lengan gaya dada; (4) latihan pernapasan; dan (5) latihan kombinasi renang gaya dada.

Proses perlakuan untuk kedua gaya (dada dan punggung) pada semua kelompok yang memiliki keterampilan baik, sedang, dan kurang terampil. Setiap tatap muka diamati tingkat kecepatan penguasaan keterampilan berenang. Berdasarkan hasil pengamatan, rata-rata untuk kelompok keterampilan berenang baik yang diajar dengan gaya crawl ke gaya punggung, terbukti dalam 1 kali pertemuan sudah dapat menguasai renang gaya punggung untuk berenang sejauh 25 meter. Rata-rata untuk kelompok baik yang diajar dengan renang gaya crawl ke gaya dada, dapat menguasai renang gaya dada memerlukan waktu minimal 4 kali pertemuan.

Rata-rata untuk kelompok keterampilan sedang yang diajar dengan renang gaya crawl ke gaya punggung memerlukan waktu minimal 3 kali pertemuan agar dapat menguasai renang gaya punggung dalam menempuh jarak sejauh 25 meter. Rata-rata untuk kelompok sedang yang diajar dengan renang gaya crawl ke gaya dada memerlukan waktu minimal 6 kali pertemuan agar dapat menguasai renang gaya dada menempuh jarak sejauh 25 meter.

Rata-rata untuk kelompok yang $\mathrm{ku}$ rang terampil diajar renang gaya crawl ke gaya punggung memerlukan waktu minimal 7 kali pertemuan baru dapat menguasai renang gaya punggung untuk berenang sejauh 25 meter. Rata-rata un- tuk kelompok kurang terampil diajar dengan renang gaya crawl ke gaya dada memerlukan waktu minimal 12 pertemuan baru dapat menguasai renang gaya dada untuk menempuh jarak 25 meter.

Berdasarkan proses jalannya penelitian seperti tersebut di atas, setelah mahasiswa menguasai keterampilan renang gaya crawl, ditemukan beberapa bukti.(1)Kelompokmahasiswa yang memiliki keterampilan renang gaya crawl baik, dalam 1 kali pertemuan sudah dapat menguasai renang gaya punggung, sedangkan untuk menguasai renang gaya dada mahasiswa memerlukan 4 kali pertemuan. (2) Kelompok mahasiswa yang memiliki keterampilan renang gaya crawl sedang, dalam 3 kali pertemuan sudah dapat menguasai renang gaya punggung, sedangkan untuk menguasai renang gaya dada mahasiswa memerlukan waktu 6 kali pertemuan. (3) Kelompok mahasiswa yang memiliki keterampilan renang gaya crawl kurang terampil, dalam 7 kali pertemuan baru dapat menguasai renang gaya punggung, sedangkan untuk menguasai renang gaya dada mahasiswa memerlukan waktu 12 kali pertemuan.

Berdasarkan hasil penelitian di atas terbukti bahwa model urutan pelajaran renang dari gaya crawl ke gaya puggung lebih efisien daripada model urutan pelajaran renang gaya crawl ke gaya dada. Hal ini dikarenakan gerak pukulan tungkai pada gaya crawl sama dengan gerak pukulan tungkai pada renang gaya punggung. Demikian juga pada gerakan lengan untuk kedua gaya (crawl dan punggung) memiliki kesamaan gerak. Dengan demikian, kedua 
gaya (crawl dan punggung) memiliki kesamaan gerak tungkai dan lengan, seddang perbedaannya terletak pada posisinya, yaitu telungkup untuk gaya crawl dan terlentang untuk gaya punggung. Dengan demikian dalam belajar renang antara gaya crawl dan gaya punggung terjadi transfer keterampilan gerak pada gerak tungkai dan lengan. Karena terjadi transfer keterampilan gerak tungkai dan lengan pada gaya crawl dan punggung, maka model urutan renang dari gaya crawl ke gaya punggung waktu yang diperlukan lebih singkat daripada model urutan dari gaya crawl ke gaya dada.

Pada model urutan renang gaya crawl yang dilanjutkan renang gaya dada tidak terjadi transfer keterampilan gerak tungkai dan lengan. Gerak pukulan tungkai pada renang gaya dada sangat berbeda dengan gerak pukulan tungkai pada renang gaya crawl. Demikian juga perbedaan terletak pada gerakan lengan antara renang gaya dada dan renang gaya crawl. Artinya, setelah menguasai renang gaya crawl, jika dilanjutkan dengan urutan renang gaya dada tidak akan terjadi transfer keterampilan pada gerak tungkai dan lengan. Akibatnya, mahasiswa agar dapat berenang gaya dada harus belajar keterampilan gerak yang baru, yaitu gerak pukulan tungkai dan lengan yang berbeda dengan gaya crawl. Hal inilah yang menyebabkan mahasiswa memerlukan waktu yang lebih lama untuk dapat menguasai renang gaya dada setelah mempelajari renang gaya crawl.

Berdasarkan fakta dan hasil penelitian ini, mulai nampak titik permasalahan yang menyebabkan mahasiswa yang mengambil mata kuliah keterampilan gerak renang banyak yang tidak lulus. Hal itu disebabkan oleh model urutan yang selama ini dijalankan menyimpang secara teori transfer keterampilan gerak (transfer of skill). Model urutan yang selama ini dijalankan adalah dari gaya crawl ke gaya dada. Padahal dari hasil penelitian ini terbukti bahwa model urutan dari gaya crawl ke gaya punggung memerlukan waktu yang lebih singkat untuk semua tingkat keterampilan (baik, sedang, dan kurang).

\section{PENUTUP}

Berdasarkan hasil penelitian dan beberapa tinjauan yang telah dikaji, dapat disimpulkan bahwa bagi mahasiswa untuk menguasai mata kuliah keterampilan gerak renang, model urutan sajian renang dari gaya crawl ke gaya punggung lebih efektif (cepat) daripada dari gaya crawl ke gaya dada.

Guna membantu percepatan kelulusan mahasiswa pada mata kuliah keterampilan gerak renang yang merupakan mata kuliah wajib lulus, maka disarankan penelitian ini populasinya perlu diperbesar lagi. Untuk itu, perlu dilakukan penelitian yang sama pada prodi lain yang ada di lingkungan FIK UNY.

Implikasi dari hasil penelitian ini dapat dijadikan sebagai bahan informasi dan pertimbangan untuk mengadakan perubahan kurikulum keterampilan gerak renang di FIK UNY. Dengan cara mengubah model urutan penyajian dari gaya crawl ke gaya dada yang selama ini dipakai, diubah dengan model urutan penyajian dari gaya crawl ke gaya punggung. Dengan perubahan model urutan penyajian tersebut di- 
harapkan kegagalan para mahasiswa untuk menguasai keterampilan gerak renang semakin berkurang. Artinya, diharapkan semakin banyak mahasiswa yang lulus mata kuliah keterampilan gerak renang di masa mendatang dengan menerapkan model sajian dari gaya crawl ke gaya punggung.

\section{UCAPAN TERIMA KASIH}

Pada kesempatan ini, penulis mengucapkan banyak terima kasih kepada Redaktur dan segenap pengurus Jurnal Cakrawala Pendidikan yang telah memberikan mimbar bagi komunikasi ilmiah ini.

\section{DAFTAR PUSTAKA}

Abdoellah, Arma, dkk. 1981. Olahraga Untuk Perguruan Tinggi. Jakarta: Sastra Budaya.

Ary, Donald, Jacobs, Lucy Cheser., Razavieh, Asghar. 1982. Pengantar Penelitian Dalam Pendidikan. (terjemahan dari Arief Furchan). Surabaya: Usaha Nasional.

Colwin, Cecil. 1977. An Introduction to Swimming Coaching. Vanier City, Ottawa, Ontario: Canadian Amateur Swimming Association.

Counsilman, James E. 1977. Competitive Swimming Manual for Coaches and Swimmer. Bloomington, Indiana: Counsilman Co., Inc.

Hadi, Sutrisno. 1965. Sendi-Sendi Eksperimen. Yogyakarta: Yayasan Pe- nerbitan FIP-IKIP Yogyakarta dengan bantuan Dep. PTIP Jakarta.

Maglischo, Ernest W. 1982. Swimming Faster. California State University, Chicago: Mayfield Publishing Company.

Nasution S. 1982. Asas-Asas Kurikulum. Bandung: Penerbit Jemmars.

Sugiyanto, F. X. 2008. "Pengembangan Urutan (Sequence) Pengajaran Renang Gaya Crawl ke Gaya Dada dengan Gaya Crawl ke Gaya Punggung terhadap Penguasaan Keterampilan Gerak Renang", Laporan Penelitian. Yogyakarta: FIK UNY.

Sugiyono. 2007. Metode Penelitian Pendidikan:Pendekatan Kuantitatif, Kualitatif, dan $R \mathcal{E} D$. Bandung: Alfabeta.

Suharsimi, Arikunto. 1996. Prosedur Penelitian. Jakarta: PT Rineka Cipta.

The Canadian Red Cross Society. 1974. National Instructor Guide and Reference. Toronto, Ontario, Canada: M4Y $1 \mathrm{H} 6$.

Tjiang, Ong Sioe dan Tarigan, Serta. 1962. Renang. Jakarta-Kota: Keng Po.

Universitas Negeri Yogyakarta. 2006. Kurikulum 2002 Fakultas Ilmu Keolahragaan. Yogyakarta: FIK-UNY. 